\title{
Distribution of soluble impurities in cold glacial ice
}

\author{
Piers R.F. BARNES, ${ }^{*}$ Eric W. WOLFF \\ British Antarctic Survey, Natural Environment Research Council, Madingley Road, Cambridge CB3 OET, England \\ E-mail:piers.barnes@csiro.au
}

\begin{abstract}
Understanding the microstructure of ice underpins the interpretation of ice-core measurements and many ice-sheet properties. A detailed study of polar snow and ice using scanning electron microscope (SEM) and X-ray analysis revealed the microstructural distribution of soluble impurities. Sublimation under vacuum (etching) concentrated impurity from both the bulk and grain boundaries on to the specimen surfaces in detectable quantities. Sublimation in the cold room before examination (preetching) collected previously unobservable quantities of impurity at triple junctions. A heterogeneous distribution of impurities was observed. Chloride was frequently found to originate from the lattice, but not usually at triple junctions. Other impurities, particularly sodium chloride, were detected at grain boundaries and bubble surfaces. Sulphate was often found at triple junctions in specimens containing a high bulk concentration of the acid, frequently in conjunction with cations. This suggests the possibility that veins were only filled with significant amounts of impurity when the surrounding grain boundaries were saturated. The model of impurity arrangement inferred from the results reconciles differences between previous SEM studies; additionally it is consistent with and explains recent electrical conduction observations. The disconnected arrangement of impurity-filled grain boundaries and veins limits opportunities for significant post-depositional solute movement.
\end{abstract}

\section{INTRODUCTION}

The arrangement of natural impurities in polar ice plays an important role in determining many of its physical properties, and is particularly relevant to the study of past climates using ice cores. The distribution has implications for (i) the possibility of post-depositional movement of chemical species (Rempel and others, 2001b), (ii) the likelihood of chemical interactions between different components trapped in the ice (Tschumi and Stauffer, 2000), and (iii) the mechanisms for electrical conduction in chemically doped ice (Wolff and others, 1997). A thorough understanding of the spatial arrangement of impurities should allow better interpretation of the ice-core measurements used to unravel the climate history. The nature of the surface of snow crystals and of the impurity on those surfaces is crucial for understanding transfer of material between the atmosphere and the upper layers of the snowpack. The great age of deep polar ice (many thousands of years old) also allows the distribution of impurities to be studied under conditions close to equilibrium, a luxury unavailable when examining laboratory-grown ice.

Virtually all precipitation nucleates on dust or aerosol particles. Of the snowflakes examined by Kumai (1976) from the South Pole, $60 \%$ had dust nuclei while $20 \%$ had nucleated on other aerosols, with the remainder of nuclei unidentifiable or unobserved. However, the majority of particulate impurity was attached to or embedded in snowflakes, but not as the nucleus. As fine-structured snowflakes

*Present address: CSIRO Industrial Physics, P.O. Box 218, Lindfield, Sydney, New South Wales 2070, Australia. sinter in the snowpack, the majority of water mass is transported via the vapour phase, with less significant transport by diffusion of mass across the surface (Colbeck, 1998). Solid particulate impurity (e.g. dust or salt aerosol below the eutectic temperature) will either associate with and possibly pin two-grain boundaries or be engulfed within the bulk of grains (e.g. Alley and others, 1986a; Weiss and others, 2002) presuming no pre-melting around the particles that could allow their expulsion from the advancing freezing front (Rempel and others, 200la). Aqueous impurities will be continuously rejected by the advancing lattice (at least at concentrations above the solubility limit) and hence remain in a liquid-like state at the ice-air surface (Wolff and Paren, 1984). Following densification, the most thermodynamically preferable location for aqueous soluble impurity is considered to be at triple junctions between grains at temperatures close to $0^{\circ} \mathrm{C}$ (Nye and Frank, 1973; Harrison and Raymond, 1976). This arrangement could explain the electrical conductivity of polycrystalline ice (Wolff and Paren, 1984). At lower temperatures the most thermodynamically stable state is not well established, although the concentration of intergranular soluble impurity is considered to be determined to a first order by the liquidus relation, with secondorder effects due to interface substrate effects and curvature. The action of interfacial forces between neighbouring grains allows a reduction in impurity concentration in a liquid-like layer when the layer approaches a molecular thickness (e.g. Wettlaufer, 1999). The extent of this effect remains poorly quantified.

Several recent studies of polycrystalline ice using the scanning electron microscope (SEM) have shown impurities in situ, both at the boundaries between ice grains and in the bulk of the crystals (Cullen and Baker, 2000, 2001; 
Barnes and Wolff: Distribution of soluble impurities in cold glacial ice

Table 1. Summary of experimental observations. The absence of observations of an impurity from a particular location and site does not preclude the possibility that it was present but not detected

$\begin{array}{ll}\text { Specimen location, } & \text { Dominant soluble impurities } \\ \text { depth } & \text { in melt, age }\end{array}$

\begin{tabular}{|c|c|c|c|}
\hline $\begin{array}{l}\text { Grain cavity surface } \\
\text { (uncut) }\end{array}$ & Grain boundary & Triple junction & Bulk and dislocations \\
\hline
\end{tabular}

\begin{tabular}{|c|c|c|c|c|}
\hline $\begin{array}{l}\text { Dome C } \\
\text { surface snow }\end{array}$ & $\begin{array}{l}{\left[\mathrm{SO}_{4}{ }^{2-}\right] \sim 0.7 \mu \mathrm{mol} \mathrm{L}^{-1}} \\
{\left[\mathrm{Na}^{+}\right] \sim 1 \mu \mathrm{mol} \mathrm{L}^{-1}} \\
{\left[\mathrm{Cl}^{-}\right] \sim 3 \mu \mathrm{mol} \mathrm{L}^{-1}} \\
<3 \text { years }\end{array}$ & $\begin{array}{l}\mathrm{Na} \text { and } \mathrm{Cl} \text { in } \\
\text { exceptional cases } \\
\text { (Fig. } 3 \mathrm{a} \text { ) }\end{array}$ & $\begin{array}{l}\text { Filament ridges often } \\
\text { observed after etching; } \\
\text { no detectable impurity } \\
\text { (Fig. } 4 \text { b) }\end{array}$ & $\begin{array}{l}\text { Only after etching were } \\
\text { filaments seen linked at } \\
\text { triple junctions in some } \\
\text { cases }\end{array}$ \\
\hline $\begin{array}{l}\text { Dome C firn, } \\
\text { low density, } 23.30 \mathrm{~m}\end{array}$ & $\begin{array}{l}{\left[\mathrm{SO}_{4}{ }^{2-}\right] \sim 1.8 \mu \mathrm{mol} \mathrm{L}^{-1}} \\
{\left[\mathrm{Na}^{+}\right] \sim 1.0 \mu \mathrm{mol} \mathrm{L}^{-1}} \\
{\left[\mathrm{Cl}^{-}\right] \sim 0.3 \mu \mathrm{mol} \mathrm{L}^{-1}} \\
\sim 390 \text { years }\end{array}$ & Not observed & $\begin{array}{l}\text { Filament ridges observed } \\
\text { on some etched surfaces }\end{array}$ & $\begin{array}{l}\text { Only after etching were } \\
\text { filaments seen linked at } \\
\text { triple junctions in some } \\
\text { cases }\end{array}$ \\
\hline $\begin{array}{l}\text { Dome C firn, } \\
\text { medium density, } \\
51.90 \mathrm{~m}\end{array}$ & $\begin{array}{l}{\left[\mathrm{SO}_{4}{ }^{2-}\right] \sim 1.2 \mu \mathrm{mol} \mathrm{L}^{-1}} \\
{\left[\mathrm{Na}^{+}\right] \sim 1.2 \mu \mathrm{mol} \mathrm{L}^{-1}} \\
{\left[\mathrm{Cl}^{-}\right] \sim 0.3 \mu \mathrm{mol} \mathrm{L}^{-1}} \\
1.1 \mathrm{kyr}\end{array}$ & $\begin{array}{l}\text { Filament observed } \\
\text { on un-etched } \\
\text { cavity surface with } \\
\text { Mg and S }\end{array}$ & $\begin{array}{l}\text { Etching concentrated } \\
\text { filaments at cut surface } \\
\text { interfaces. Cl and trace S } \\
\text { detected }\end{array}$ & $\begin{array}{l}\text { Some triple junctions } \\
\text { joined by filaments after } \\
\text { etching }\end{array}$ \\
\hline
\end{tabular}

Dome C firn,

high density,

$95.8 \mathrm{~m}$

Dome C

small sulphate

peak, $140.05 \mathrm{~m}$

Dome C

medium sulphate

peak, $218.95 \mathrm{~m}$

Dome C

large sulphate

peak, $243.30 \mathrm{~m}$

Dome C

background to

sulphate peak,

$243.50 \mathrm{~m}$

Dome C,

269.5-270.05 m

Dome C,

500.5-501.05 m

Halley surface snow

Dronning Maud Land, 115 m

\footnotetext{
$\left[\mathrm{SO}_{4}{ }^{2-}\right] \sim 1.0 \mu \mathrm{mol} \mathrm{L}^{-1}$

$\left[\mathrm{Na}^{+}\right] \sim 0.8 \mu \mathrm{mol} \mathrm{L}^{-1}$

$\left[\mathrm{Cl}^{-}\right] \sim 0.4 \mu \mathrm{mol} \mathrm{L}^{-1}$

$8.4 \mathrm{kyr}$
}

$\left[\mathrm{SO}_{4}{ }^{2-}\right] \sim 1.2 \mu \mathrm{mol} \mathrm{L}^{-1} \quad$ Not observed
$\left[\mathrm{Na}^{+}\right] \sim 1.2 \mu \mathrm{mol} \mathrm{L}^{-1}$
$\left[\mathrm{Cl}^{-}\right] \sim 0.2 \mu \mathrm{mol} \mathrm{L}^{-1}$
$2.3 \mathrm{kyr}$

$\left[\mathrm{SO}_{4}{ }^{2-}\right] \sim 1.6 \mu \mathrm{mol} \mathrm{L}^{-1} \quad$ Not observed

$\left[\mathrm{Na}^{+}\right] \sim 1.1 \mu \mathrm{mol} \mathrm{L}^{-1}$

$\left[\mathrm{Cl}^{-}\right] \sim 0.4 \mu \mathrm{mol} \mathrm{L}^{-1}$

$3.7 \mathrm{kyr}$

$\left[\mathrm{SO}_{4}{ }^{2-}\right] \sim 2.9 \mu \mathrm{mol} \mathrm{L}^{-1}$

$\left[\mathrm{Na}^{+}\right] \sim 0.7 \mu \mathrm{mol} \mathrm{L}^{-1}$

$\left[\mathrm{Cl}^{-}\right] \sim 0.4 \mu \mathrm{mol} \mathrm{L}^{-1}$

$6.6 \mathrm{kyr}$

$\left[\mathrm{SO}_{4}{ }^{2-}\right] \sim 5.2 \mu \mathrm{mol} \mathrm{L}^{-1}$

$\left[\mathrm{Na}^{+}\right] \sim 0.8 \mu \mathrm{mol} \mathrm{L}^{-1}$

$\left[\mathrm{Cl}^{-}\right] \sim 0.2 \mu \mathrm{mol} \mathrm{L}^{-1}$

$7.5 \mathrm{kyr}$

$\left[\mathrm{SO}_{4}{ }^{2-}\right] \sim 1.3 \mu \mathrm{mol} \mathrm{L}^{-1}$

$\left[\mathrm{Na}^{+}\right] \sim 1.0 \mu \mathrm{mol} \mathrm{L}^{-1}$

$\left[\mathrm{Cl}^{-}\right] \sim 0.3 \mu \mathrm{mol} \mathrm{L}^{-1}$

$7.5 \mathrm{kyr}$

$\left[\mathrm{SO}_{4}{ }^{2-}\right] \sim 2.7 \mu \mathrm{mol} \mathrm{L}^{-1}$

$\left[\mathrm{Na}^{+}\right] \sim 4 \mu \mathrm{mol} \mathrm{L}^{-1}$

$\left[\mathrm{Cl}^{-}\right] \sim 4 \mu \mathrm{mol} \mathrm{L}^{-1}$

$20.2 \mathrm{kyr}$

$\left[\mathrm{SO}_{4}{ }^{2-}\right] \sim 0.9 \mu \mathrm{mol} \mathrm{L}^{-1}$

$\left[\mathrm{Na}^{+}\right] \sim 18 \mu \mathrm{mol} \mathrm{L}^{-1}$

$\left[\mathrm{Cl}^{-}\right] \sim 21 \mu \mathrm{mol} \mathrm{L}^{-1}$

$<3$ years

Al and $\mathrm{S}$ spots

observed on the

rims of bubbles

during etching

Filament and spots coagulated on rim of bubbles during

etching containing

$\mathrm{Na}$ and $\mathrm{Cl}$ (Fig. 3b)

Not observed

Not observed

$\left[\mathrm{SO}_{4}{ }^{2-}\right] \sim 1.4 \mu \mathrm{mol} \mathrm{L}^{-1}$

$\left[\mathrm{Na}^{+}\right] \sim 1.0 \mu \mathrm{mol} \mathrm{L}^{-1}$

$\left[\mathrm{Cl}^{-}\right] \sim 1.4 \mu \mathrm{mol} \mathrm{L}^{-1}$

$1.2 \mathrm{kyr}$

GRIP,

1312.30-1312.85 m

$\left[\mathrm{SO}_{4}{ }^{2-}\right] \sim 0.3 \mu \mathrm{mol} \mathrm{L}^{-1}$

$\left[\mathrm{Na}^{+}\right] \sim 0.3 \mu \mathrm{mol} \mathrm{L}^{-1}$

$\left[\mathrm{Cl}^{-}\right] \sim 0.3 \mu \mathrm{mol} \mathrm{L}^{-1}$

$7.9 \mathrm{kyr}$

GRIP,

$\left[\mathrm{SO}_{4}{ }^{2-}\right] \sim 2.8 \mu \mathrm{mol} \mathrm{L}^{-1}$

$\left[\mathrm{Na}^{+}\right] \sim 3.5 \mu \mathrm{mol} \mathrm{L}^{-1}$

$\left[\mathrm{Cl}^{-}\right] \sim 3 \mu \mathrm{mol} \mathrm{L}^{-1}$

$23.2 \mathrm{kyr}$

Not observed

Not observed
Not observed

Most boundaries did not reveal filaments when etched

Many boundaries did not reveal filaments when etched

Filaments seen at some grain boundaries after etching

Distinct etching filaments produced in some cases, containing a variety of species including $\mathrm{Na}, \mathrm{Cl}$, S, K and Ca (Fig. 4e)

Distinct etching filaments containing $\mathrm{Na}$ and $\mathrm{Cl}$

(Fig. 3b) junctions after pre-

Filament ridges not generally observed after minor etching

Filament ridges occasionally apparent during etching

Filaments observed at grain boundaries after etching (Fig. 4a); detectable $\mathrm{S}$ and $\mathrm{Na}$ noted at one (Fig. 4d)

$\mathrm{Na}$ and Cl clearly detected in a thick layer at pre-etched grain boundaries in one specimen; grain boundary filament ridges also noted (Fig. 5c)

Filament ridges observed sometimes during etching; detectable $\mathrm{Cl}$ noted in one case

Majority of grain

boundaries clear of

filament ridges
Not observed even after etching

Low levels of $\mathrm{S}$ and $\mathrm{Na}$ detected directly in triple etching

$\mathrm{S}, \mathrm{Na}$ and at many triple junctions after preetching (Fig. 5f)

Triple junctions containing S (Fig. 5d), and others containing a mixture of $\mathrm{Na}, \mathrm{S}$ and $\mathrm{K}$ and $\mathrm{Ca}$ (Fig. 5e) detected after surface pre-etching

No impurity detected even after long pre-etch periods

$\mathrm{Cl}$ detectable in surface etch spots after heavy etching

$\mathrm{Si}, \mathrm{S}$ and $\mathrm{Cl}$ detected in mobile particles revealed by heavy etching

Etching revealed many coagulated spots close to grain-boundary filaments containing $\mathrm{Cl}$ and trace $\mathrm{Na}$; other background spots contained trace $\mathrm{Cl}$

Surface etch spots containing $\mathrm{S}$ and $\mathrm{Cl}$ revealed on etching

$\mathrm{Cl}$ detected in surface etching spots

$\mathrm{Cl}$ alone as well as $\mathrm{Na}$ and $\mathrm{Cl}$ detected in surface etching spots (Fig. 6a)

Surface etching spots containing $\mathrm{Cl}$ and occasionally Na revealed (Fig. 4e)

Etching revealed inclusions of $\mathrm{Na}$ and $\mathrm{Cl}$, also possible dislocations containing $\mathrm{Na}$ and $\mathrm{Cl}$; surface etch spots had a similar composition (Fig. 6b)

Not observed

$\mathrm{Cl}, \mathrm{S}$ and Na detected in surface etching spots

Incidence of $\mathrm{Na}$ and $\mathrm{Cl}$ noted at TJ after brief etching with no preetching (Fig. 5c)

Etching filaments joined at triple junctions

$\mathrm{Na}$ and $\mathrm{Cl}$ inclusions noted during etching

Impurity not detected in surface etching spots

Pre-etched triple junctions noted containing $\mathrm{Na}, \mathrm{Mg}, \mathrm{Al}$, $\mathrm{S}, \mathrm{Cl}, \mathrm{K}$ and $\mathrm{Ca}$; possible dust particle in vein

Not observed, other than joining etched ridges

$\mathrm{Cl}$ and $\mathrm{Mg}$ detected in some surface etching spots, as well as inclusions

Not observed

Inclusions containing multiple impurity species revealed by etching 
Baker and Cullen, 2002; Barnes and others, 2002b). Prior to these only a couple of direct studies on impurity location had been published. Mulvaney and others (1988) and Wolff and others (1988) used the SEM and X-ray analysis to show sulphur inferred to be sulphuric acid at triple junctions in ice from Dolleman Island, Antarctica. Fukazawa and others (1998) found acidic $\mathrm{SO}_{4}{ }^{2-}, \mathrm{NO}_{3}{ }^{-}$and $\mathrm{HSO}_{4}{ }^{-}$as liquids at triple junctions using Raman spectroscopy in ice from both Nansen and South Yamoto, Antarctica. The conclusions from these different studies do not present a fully coherent description of either the arrangement of impurities or the factors that determine it. Mulvaney and others (1988) suggested that the majority of acid present in the ice might be located at triple junctions. The results of Fukazawa and others (1998) indicated a high proportion of the available acid was located in veins at Nansen but a much lower proportion at South Yamoto. Cullen and Baker (2000, 2001) concluded that a far greater proportion of impurity present was located at two-grain boundaries and as inclusions in the bulk, in ice from the Greenland Ice Sheet Project 2 (GISP2) core and from the Byrd core in Antarctica (Cullen and Baker, 2000, 2001).

This study provides further detailed experimental information to help resolve the issue. It describes the analysis of ice taken from four different sites, but concentrates on ice sampled from the Dome G (Antarctica) ice core. The range of ages, depths, chemical compositions and temperatures of the ice used in the work allows the differing factors controlling impurity location to be assessed. Low-temperature scanning electron microscopy and X-ray analysis are used to search the microstructure for impurities. A description of the technique employed is provided, including variations to the previously published method, and an attempt to quantify X-ray analysis measurements (section 2). The results in section 3 indicate that impurities are present in a wide range of locations, including vapour-solid interfaces, grain boundaries, triple junctions and in the lattice (either dissolved at point defects or included). There are many sources of uncertainty when understanding the images and spectra collected. However, using our interpretation of these observations, we infer the preferred arrangement of the main impurity species within the ice, both intergranular and within the lattice (section 4). Some of the implications of such a distribution for ice-core research are also considered.

\section{METHOD}

Specimens were taken from the following sites: the Dome $\mathrm{C}$ core, drilled in $1999\left(75^{\circ} 06^{\prime} \mathrm{S}, 123^{\circ} 21^{\prime} \mathrm{E}\right.$; $3233 \mathrm{~m}$ elevation and $-54.5^{\circ} \mathrm{C}$ mean annual temperature), a Dronning Maud Land (Antarctica) core drilled in $1998\left(77^{\circ} \mathrm{S}, 10^{\circ} \mathrm{W} ; 2200 \mathrm{~m}\right.$ elevation and $-38^{\circ} \mathrm{C}$ mean annual temperature), surface snow collected in 1999 from the clean area near Halley station, Antarctica, situated on the Brunt Ice Shelf $\left(75^{\circ} 35^{\prime} \mathrm{S}\right.$, $26^{\circ} 30^{\prime} \mathrm{W}$; $32 \mathrm{~m}$ elevation and $-19.3^{\circ} \mathrm{C}$ mean annual temperature), and the Greenland Icecore Project (GRIP) ice core drilled in $1990\left(72^{\circ} 34^{\prime} \mathrm{N}, 37^{\circ} 37^{\prime} \mathrm{W}\right.$; $3232 \mathrm{~m}$ elevation and $-32^{\circ} \mathrm{C}$ mean annual temperature). All specimens were stored in a cold room at $-20^{\circ} \mathrm{C}$ before examination. Table 1 lists the sites, depths, ages and chemical concentrations of sulphate, chloride and sodium ions measured in the meltwater (Röthlisberger and others, 2000; Udisti and others,
2000). All samples were from relatively acidic ice of Holocene age except for samples from the last glacial period from Dome G (501 m), and GRIP samples at $1980 \mathrm{~m}$ depth in which much of the acid has been neutralized by alkaline dust in the ice. The four different sites were used to provide ice of varying composition for the study rather than for the purpose of making climatic comparisons between the sites.

The samples were prepared and examined using the technique outlined in detail by Barnes and others (2002c), with minor modifications included in the following description. Samples of approximately $5 \mathrm{~mm}$ diameter were cut and mounted on brass stubs in the isolated environment of a cold room at $-20^{\circ} \mathrm{C}$, using cleaned forceps handled wearing latex gloves to prevent condensation. Flat surfaces were achieved using a sledge microtome. Pre-etching (leaving the specimen to stand in a sealed container in the cold room) was used in some cases to smooth the cutting fractures and defects as well as to enhance grain-boundary grooves by preferential sublimation at the high-energy-density boundary sites under vapour saturation conditions. Specimens were protected from contamination and condensation using a brass cap that was tipped off the specimen upon insertion into the cryo-chamber of the microscope. This eliminated the need to sublimate frost from the surface by etching, which was required in other studies (e.g. Adams and others, 2001). Samples were always cooled by immersion in liquid nitrogen $\left(-196^{\circ} \mathrm{C}\right)$ before being introduced to the SEM. This prevented the rapid surface sublimation and consequent impurity redistribution that occurs on exposing a comparatively warm surface $\left(\sim-20^{\circ} \mathrm{C}\right)$ to a vacuum, as was done in other studies (e.g. Cullen and Baker, 2001).

The ice was examined with a Leica S360 SEM fitted with an Oxford Instruments CT1500 cold stage and an Oxford Instruments INCA system with an ATW germanium energy-dispersive detector for X-ray microanalysis. A beam power of $15 \mathrm{kV}$ and $500 \mathrm{pA}$ was used for all microanalysis in this study, and samples were maintained at temperatures of -120 to $-130^{\circ} \mathrm{C}$ (as used by Cullen and Baker, 2001, increased from $-160^{\circ} \mathrm{C}$ in our previous study) reducing the effects of surface charging to an acceptable level. These temperatures allow enough sublimation for excess charging on the surface to be masked by the ionized vapour, while not significantly altering the surface topography (sublimation rate $<10 \mathrm{~nm} \mathrm{~min}^{-1}$ (Davy and Branton, 1970)). X-ray spectra were generally collected for an 80 s live time. The beam was retargeted throughout collection to overcome problems of thermal drift.

To gather additional information about the microstructure, etching was used to sublimate more significant amounts of ice from the surface while leaving impurities to coagulate on the surface as hydrated salts. There is a possibility that the more volatile impurities (e.g. $\mathrm{HCl}$ ) might be lost from the surface during etching at high temperatures. The sublimation rate was controlled by raising the temperature of the sample stage to $-80,-70$ or $-60^{\circ} \mathrm{C}$ achieving etching rates on a flat surface of 6, 20 or $60 \mu \mathrm{m} \mathrm{min}^{-1}$ (Davy and Branton, 1970; Barnes and others, 2002a).

\subsection{X-ray analysis calibration}

It is difficult to adequately calibrate X-ray measurements where an impurity of size less than the excitation volume is surrounded by a medium of different conductivity. To calibrate X-ray analysis measurements, Reid and others (1992) 

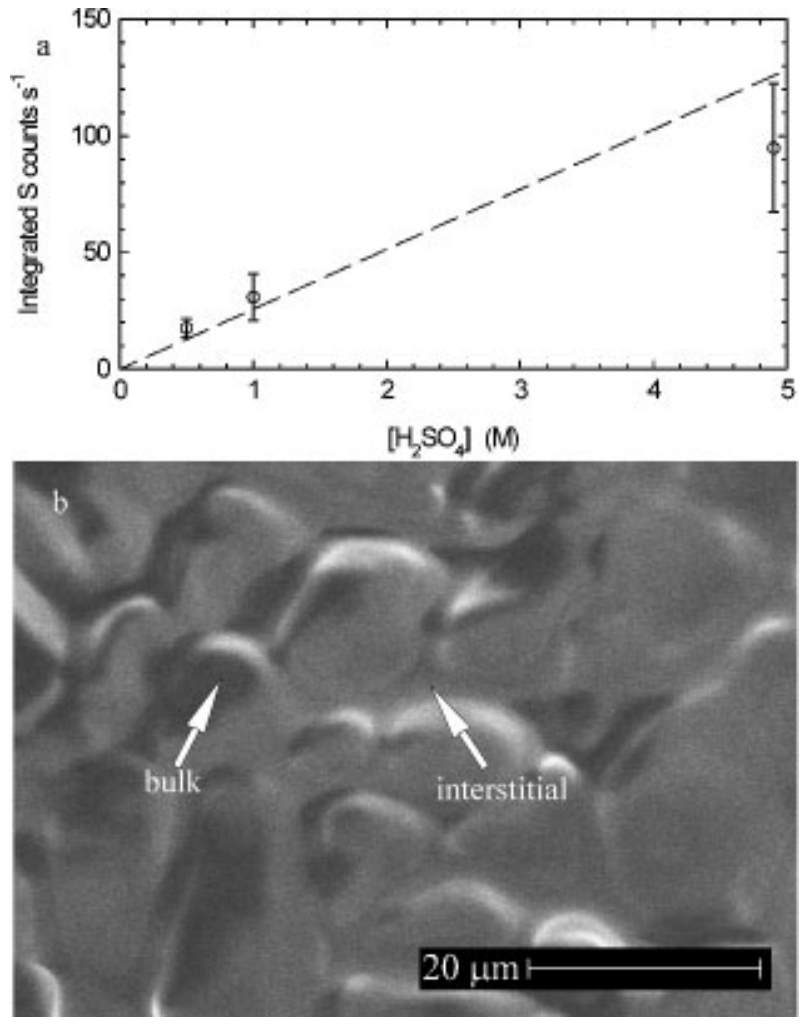

Fig. 1. (a) The relationship between integrated count rate collected by $X$-ray analysis and concentration of sulphuric acid frozen into $0.4 \mu \mathrm{m}$ holes (error bars give standard deviation of measurements). (b) Cut surface of frozen $0.5 \mathrm{~mol} \mathrm{~L}^{-1}$ sulphuric acid (uncoated). Partitioning can be clearly seen between the bulk ice and the interstitial acidic components.

froze aqueous standards into track-etched (Nuclepore) filters to simulate impurity-filled veins in ice. Constraining the acid in the filter holes prevented significant partitioning of the impurity phase during freezing. They found a linear relationship between elemental concentration and the X-ray count rate stimulated by the incident electron beam. Here the calibration was repeated, this time using sulphuric acid solutions without a surface coating to replicate conditions in this study. Acids of $0.5,1.0$ and $4.9 \mathrm{~mol} \mathrm{~L}^{-1}$ (the eutectic concentration) were used, frozen into $0.4 \mu \mathrm{m}$ pores in the polycarbonate membrane. The technique involved rapidly freezing the saturated filters between liquid-nitrogen-cooled copper blocks. The absence of a conductive coating allowed a large variation in the detected X-ray count rates; however, an approximately linear relationship was still seen between the integrated elemental count rate for sulphur and the acid concentration (Fig. la). The presence of a small carbon peak in the collected spectra indicated that the X-ray excitation volume extended beyond the circumference of the holes. The count rates were even more variable for the same acids frozen into larger pore sizes $(2$ and $8 \mu \mathrm{m}$ ), suggesting that impurity segregation was occurring in the frozen mixture.

We make a crude estimate of the minimum quantity of sulphate detectable on an ice surface under the conditions in this study. The shape and volume of interaction of electrons within ice is not well established, particularly in the presence of impurities (Echlin, 1992). Early work by Brombach, as well as Fuchs and Lindeman, suggested the conversion of the interaction volume from pear to pancake shape ( $400 \mathrm{~nm}$ wide, $100 \mathrm{~nm}$ deep with the beam accelerated by

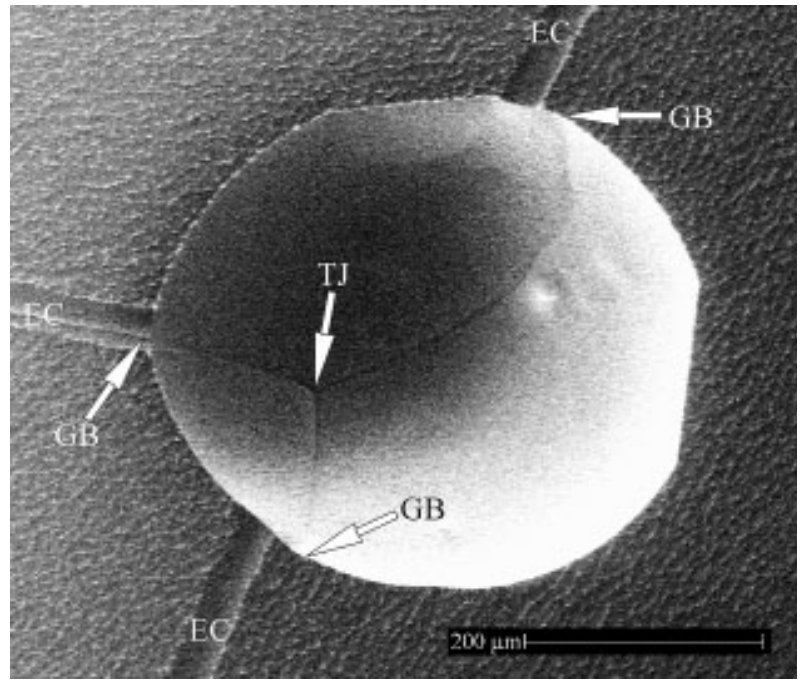

Fig. 2. The intersection of the etching surface with the grainboundary grooves on the bubble cavity surface, marked by arrows ( scale bar $200 \mu \mathrm{m}$ ). The ice taken from $140 \mathrm{~m}$ at Dome Chad been cut and pre-etched for 1 day at $-20^{\circ} \mathrm{C}$ before being etched for $10 \mathrm{~min}$ at $-70^{\circ} \mathrm{C}$ in the SEM. Note the mismatch between the grain-boundary location $(G B)$ and the etch channels (EC) on the cut surface; there is no sign of the grain boundary on the surface when the two do not match.

$5 \mathrm{kV}$ ) after several seconds of exposure on a pure ice surface (reviewed by Echlin, 1992). In contrast to this, Oates and Potts (1985) detected sulphur from below an ice layer $3 \mu \mathrm{m}$ thick when it was stimulated with electrons accelerated by $15 \mathrm{kV}$; however, $90 \%$ of X-ray emission should occur within the top $2 \mu \mathrm{m}$. Based on these latter results, the volume of acid stimulated in a hole of diameter $0.4 \mu \mathrm{m}$ is approximately $0.25 \mu \mathrm{m}^{3}$; if the acid is at $0.5 \mathrm{~mol} \mathrm{~L}^{-1}$ then the signal emitted originates from $1.3 \times 10^{-16} \mathrm{~mol}$ of sulphur. In this study, a signal around five times less than this was no longer distinguishable from a background spectrum. Given a linear relationship between count rate and impurity concentration (Fig. la), this indicates that the minimum detectable quantity of sulphur is about $3 \times 10^{-17} \mathrm{~mol}$. We estimate the minimum detectable quantities for $\mathrm{Na}, \mathrm{Mg}$ and $\mathrm{Cl}$ to be factors of 2.6, 1.0 and 1.5 greater, respectively, than the value for sulphur (Reid and others, 1992).

It is generally presumed that the frozen solution formed between rapidly cooled ice grains is at the eutectic composition regardless of the bulk ice concentration if curvature and substrate effects are negligible. This is expected for liquid components of the polar specimens in this study on freezing in liquid nitrogen. To test whether this is the case, sulphuric acid droplets of varying concentration were rapidly frozen on a copper block cooled by immersion in liquid nitrogen $\left(-196^{\circ} \mathrm{C}\right)$. Flat surfaces were microtomed for the 0.5 (see Fig. 1b) and $1 \mathrm{~mol} \mathrm{~L}^{-1}$ droplets, but the $4.9 \mathrm{~mol} \mathrm{~L}^{-1}$ droplet (the eutectic concentration) was left uncut as a droplet since it would be liquid at the cutting temperature of $-20^{\circ} \mathrm{C}$. No sulphur is detectable from the surfaces of the ice grains, but it is clearly present in the interstitial regions surrounding the small rapidly formed grains. If the interstitial solution is at the eutectic composition in all cases, we expect similar count rates from each droplet. The net sulphur peak count-rate integrals of the measured spectra were $53 \pm 39$, $102 \pm 75$ and $36 \pm 9$ counts per second for the 0.5, 1.0 and $4.9 \mathrm{~mol} \mathrm{~L}^{-1}$ specimens, respectively (a minimum of five 

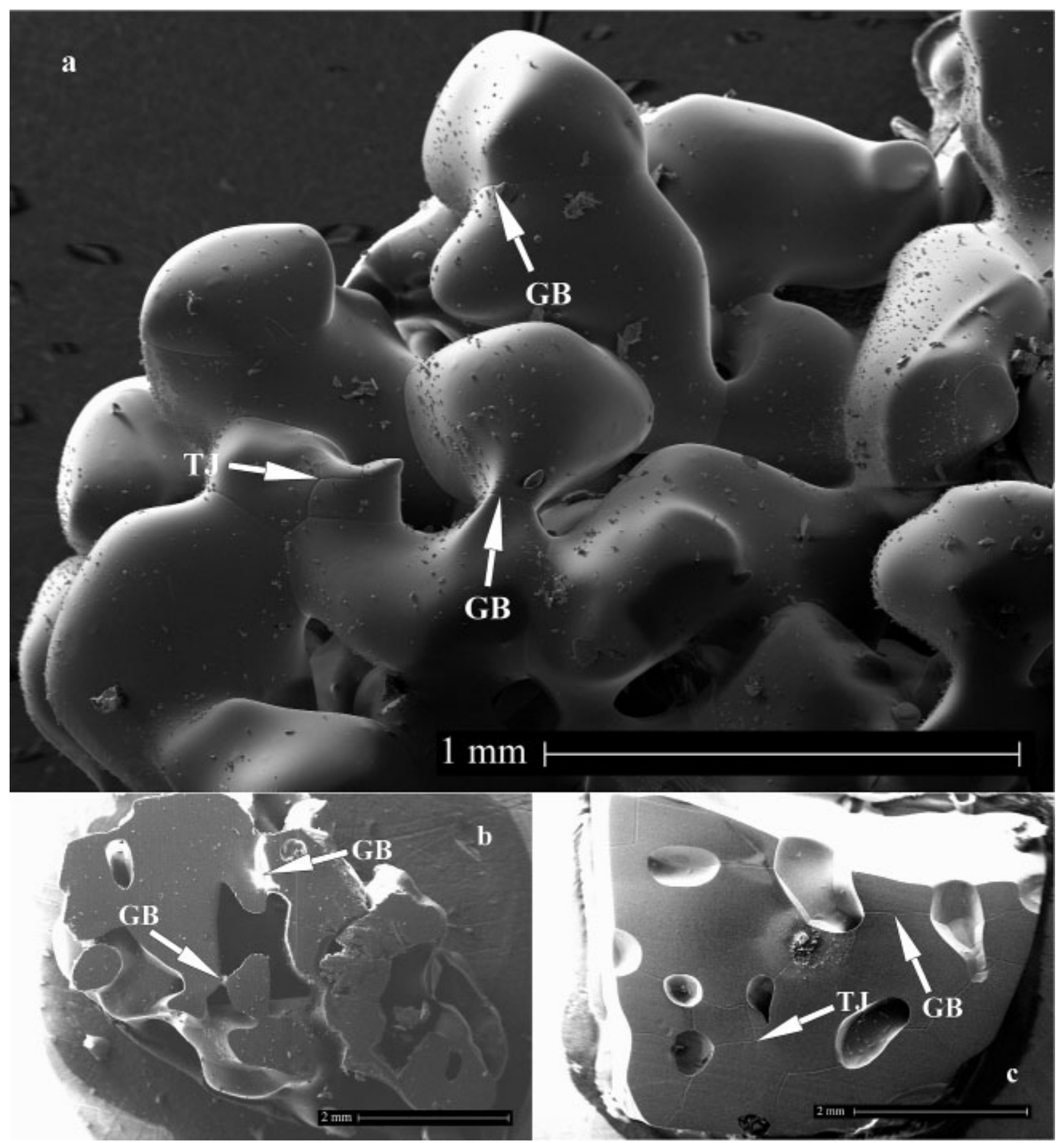

Fig. 3. Dome C snow and firn. Examples of the location of grain boundaries (GB) and triple junctions (Tf) marked. (a) Sintering surface snow, with a density of approximately $340 \mathrm{~kg} \mathrm{~m}^{-3}$. No etching has been performed on this specimen. Grain-boundary grooves can be seen at the necks between grains. Small ice crystals suspended in the liquid nitrogen used to cool the ice have been deposited on the surface. (b) Firn from $23.3 \mathrm{~m}$ depth with an approximate density of $526 \mathrm{~kg} \mathrm{~m}^{-3}$. The surface has been cut to reveal an un-etched section. (c) Firn from $95.8 \mathrm{~m}$ with a density of $820 \mathrm{~kg} \mathrm{~m}^{-3}$ around the pore close-off depth. The surface has been cut, pre-etched for 1 day and then etched in the SEM for 10 min at $-70^{\circ} \mathrm{C}$ to reveal the location of the grainboundary grooves more clearly.

spectra were used for each measurement). Because of the effects of charging, and of geometry in the concentrated drop, the results are very variable and we can only say that the concentrations of the interstitial solution are high and do not rule out a uniform interstitial composition.

\subsection{Interpreting etching}

Understanding the features of an etched surface is important when ascertaining the origin of observed impurity. As shown by Barnes (2003), the location of etching channels formed on a surface by rapid sublimation under vacuum conditions (etching) does not necessarily coincide with the location of the grain boundary on the surface. This is exemplified by the bubble cavity embedded in an etched surface shown in Figure 2. The grain-boundary grooves visible in the bubble cavity, a site where less sublimation occurred because of curvature, do not match the location of the surface etching channels at the top and bottom of the image. The location of the grain boundary on the cut surface is only seen when it is congruent with the relatively smooth base of the etching channel; in this case a ridge is noted, probably forming because of the coagulation of hydrated impurity salts concentrated at the boundary. Numerous other 
examples were noted during this study where, after etching, previously connected grooves at surface-cavity interfaces no longer matched.

The effect is expected because of the difference between pre-etching and etching. The grain-boundary grooves that initially form under vapour saturation conditions during pre-etching balance the surface free energies at the interface. During sublimation under a vacuum (etching) the vapour pressure above the surface is no longer at or close to its saturation point. Consequently the observed etching channels develop because of the topological features present on the surface at the start of etching, not because of the presence of the higher-energy density at the grain boundary (an un-pre-etched surface produces no discernible etching channels because the grain-boundary grooves are so small).

Consequently, grain boundaries and triple junctions on an etched surface will only be distinguishable by surface fabric differences, unless they coincide with etching channels. We expect that, during etching, any impurity at a grain boundary perpendicular to the surface will coagulate as a filament (a slender, thread-like body) on the retreating surface; however, it could also coagulate to form discrete particles or evaporate from the surface if sufficiently volatile. Impurity at a grain boundary or vein that is not parallel with the direction of etching will be spread across the retreating surface, ending up as coagulated surface spots. Some data in previous studies using etching should be reevaluated in light of this.

\section{RESULTS}

This section presents evidence gathered using the SEM, from the examination of more than 100 samples collected from the four sites at a wide range of depths. The images show some of the clearer examples pertaining to soluble impurities in the ice. Most impurity species could be found in a range of different locations, and considerable variation was found even between specimens from an identical depth. General observations concerning specimens from each location are summarized in Table 1 .

\subsection{Snow and firn}

Figure 3 shows images of surface snow through to firn at the pore close-off depth. The complex faceted structures observed in snow crystals (Rango and others, 1996a) and diamond dust (Kumai, 1976) rapidly sinter and densify to the observed smooth-surfaced structures similar to those observed by Rango and others (1996b). Grain-boundary grooves and triple junctions are apparent between the grain surfaces and at the necks between crystals. The dihedral contact angle was measured at grain boundaries between sintering snow crystals in instances where the bond between grains was perpendicular to the angle of observation, and the specimen had not been etched. Measurements of grain boundaries at 13 bonds from three different specimens (two from Halley, one from Dome $\mathrm{G}$ ) gave a mean air-ice dihedral angle of $132 \pm 3^{\circ}$.

\subsection{Pore surface impurity}

Soluble impurity was detected on un-etched cavity (vapour-ice) surfaces, both on snow grains and on bubble walls. Figure 4 shows examples of both of these features in Dome $\mathrm{C}$ snow and ice. It should be noted that impurity

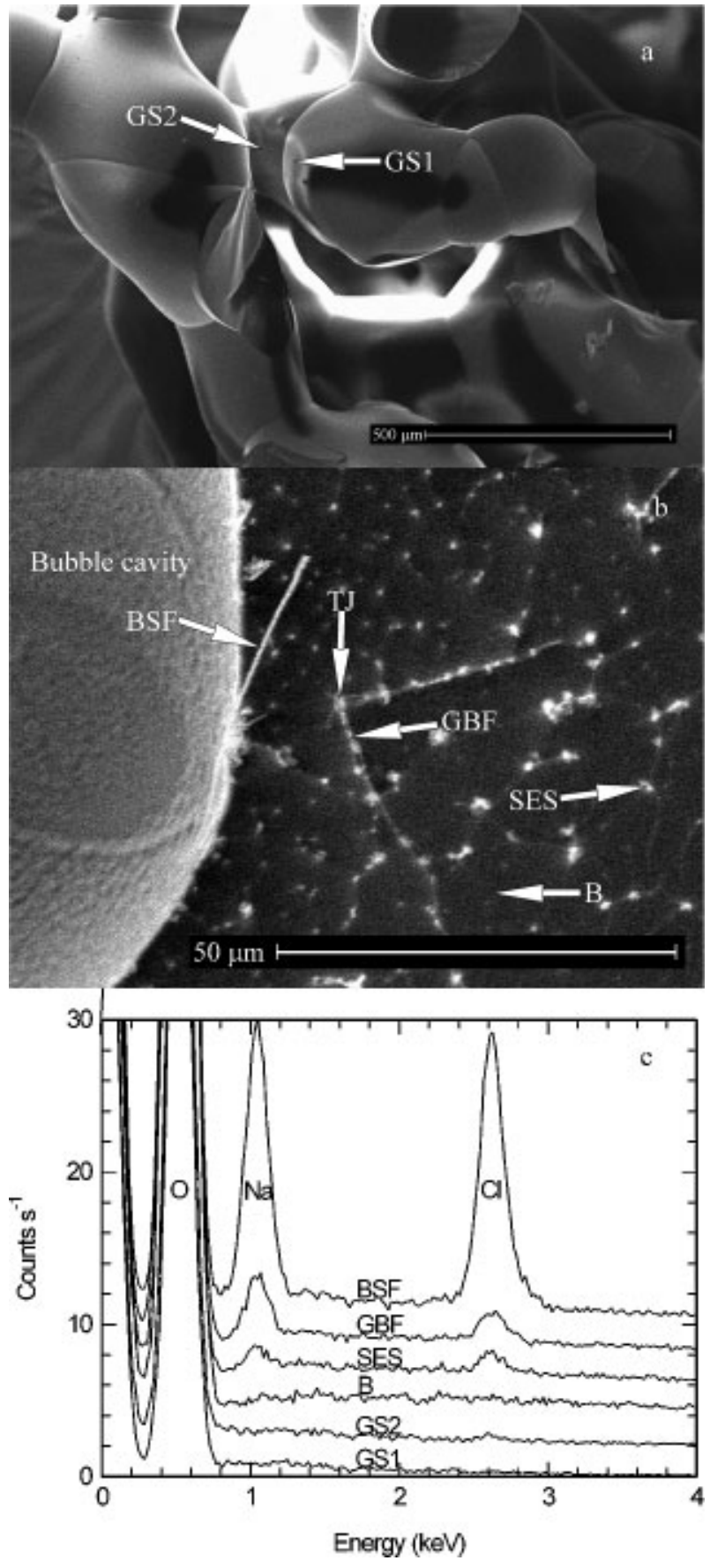

Fig. 4. Surface impurity. (a) Surfaces of sintering surface snow grains from Dome $C$; the surfaces shown are un-etched ( scale bar $500 \mu \mathrm{m}$ ). Traces of chlorine were detectable on some grain surfaces. Grain surface 1 (GS1) showed no detectable impurity. However, the adjacent grain surface (GS2) consistently showed traces of chlorine at the detection limit; if sodium was also present, it was below the detection limit. (b) Section of a bubble wall, from Dome C $243.50 \mathrm{~m}$ (scale bar $50 \mu \mathrm{m})$. The surface has been pre-etched for 1 day and then etched for 8 min at $-70^{\circ} \mathrm{C}(\sim 400 \mu \mathrm{m}$ removed $)$. The bubble surface filament (BSF) is a hydrated salt coagulated from the surface of the bubble at its rim during etching and has a width of $\sim 2 \mu \mathrm{m}$. A grain-boundary filament $(G B F$ ) has also formed at the original location of the grain boundaries on the un-etched surface; the position of the filament triple junction (TJ) is marked. During etching, spots of impurity also coagulate on the surface (SES), while no impurity can be detected in the dark background areas (e.g. B). (c) X-ray spectral data for (a) and (b), offset by multiples of 2 counts $^{-1}$. 


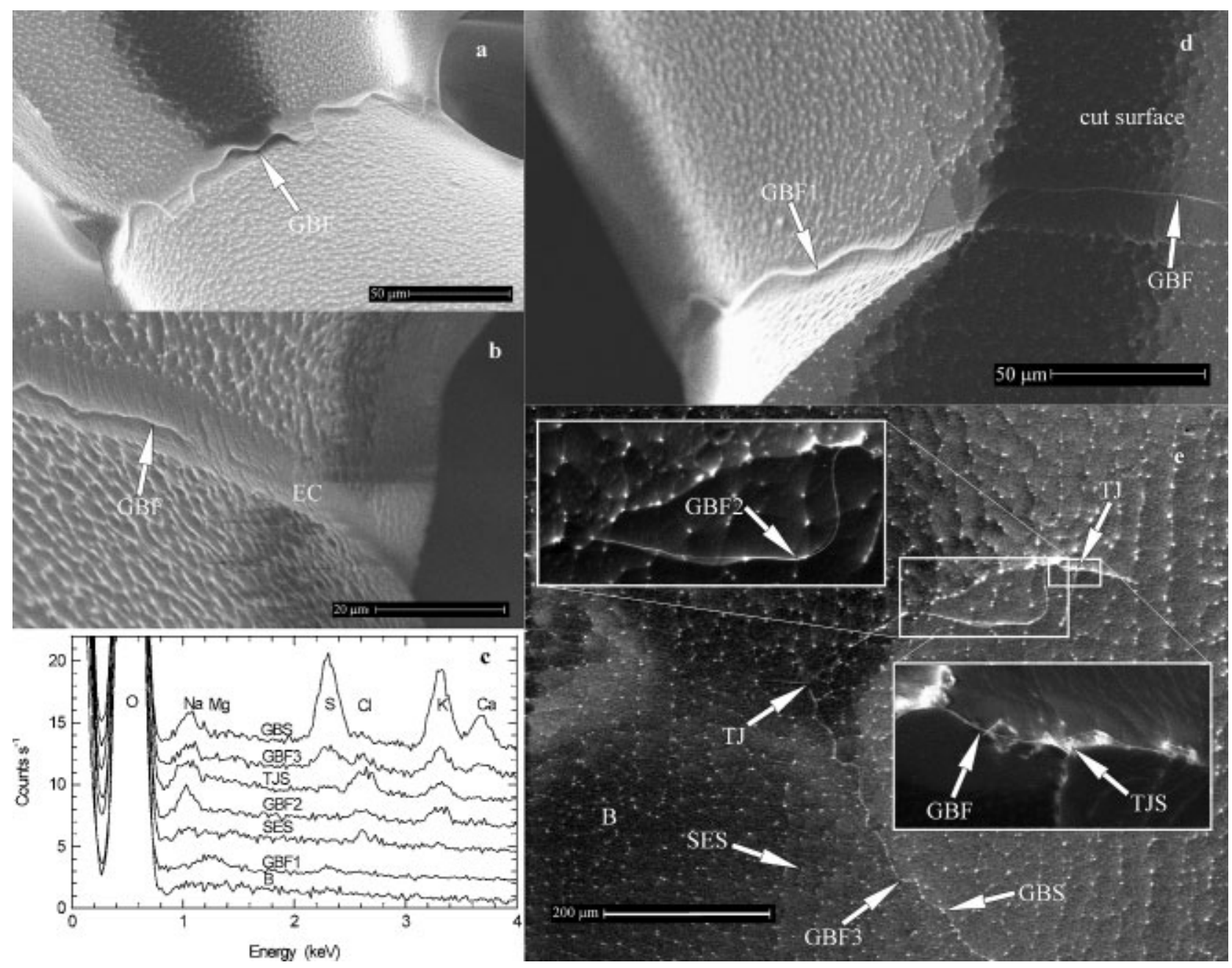

Fig. 5. Impurity at grain boundaries. (a) Neck between grains of sintering surface snow from Halley. The specimen has been etched for the equivalent of 6 min at $-70^{\circ} \mathrm{C}$. A grain-boundary filament $(G B F)$ has developed at the neck during etching. Its tortuous appearance suggests that it has buckled as the neck's radius reduces with sublimation. No impurity was directly detectable in this filament. (b) A similar neck between grains of Dome C surface snow. The specimen has been etched for 4 min at $-70^{\circ} \mathrm{C}$. A grain-boundary filament has developed in the etching channel (EC) formed at the location of the grain-boundary groove. Note that the filament, which did not contain detectable impurity, is not continuous around the boundary, suggesting that the bond is only partially covered by an impurity layer. (c) X-ray spectra for many of the points marked with arrows in (d) and (e), offset by multiples of 2 counts $s^{-1}$. ( $d$ ) A bond between grains of Halley surface snow that has been cut by the microtome, pre-etched for 1 day, and then etched in the SEM for the equivalent of 6 min at $-70^{\circ} \mathrm{C}$. A grain-boundary filament has developed at the etching channel on both the snow grain surface and the cut surface. The filament on the snow grain surface, which has split into two strands during etching, contained detectable magnesium and sulphur (GBF1) while no impurity was detectable in the filament on the cut surface. (e) Dome C ice from $243.30 \mathrm{~m}$ depth. The surface has been cut but not preetched, and then etched in the SEM for 10 min at $-60^{\circ} \mathrm{C}(600 \mu \mathrm{m})$. A clear grain-boundary filament has been produced, apparently joined at triple junctions (T7); it can be seen in the insets and has a diameter of approximately $400 \mathrm{~nm}$. Spectra were taken from the filament (GBF2, GBF3) and also from the surface spots (GBS) that have formed by the coagulation of the grain-boundary filament during etching and the triple junction (T 7S). Spectra were also collected from typical background surface etching spots (SES) and from the dark areas of the background (B).

detected on an un-etched cavity surface was not common. The filament of $\mathrm{NaCl}$ associated with the rim of the bubble in Figure 4b has coagulated from the bubble surface during etching, and has a similar composition to other impurities noted on the sublimating surface. Coagulating spots of impurity were also seen on the rims of bubbles from other depths (Table 1).

\subsection{Impurity at grain boundaries}

Occasionally impurity could be located at grain boundaries without etching (Barnes and others, 2002b; Barnes, 2003). However the examples of impurity found at grain boundaries shown here were all revealed by the use of surface etching, since impurity is not usually detectable on a freshly cut or pre-etched surface. Caution must be exercised when interpreting any etched surface, since the process of sublimation can enhance the mobility of some coagulated impurities and obscure their original location, as discussed in section 2.2. Figure 5 shows examples of impurity filaments, coagulated filaments and impurity ridges originating from grain boundaries. Images from the etched necks of snow crystals at Halley (Fig. 5a and d) and Dome C (Fig. 5b and e) are seen. The etch rate from snow surfaces is likely to be generally lower than for flat cut surfaces because of the porous structure. The tortuous path of the filaments at bonds between neighbouring grains suggests an impurity component with some structural strength under compression. As 

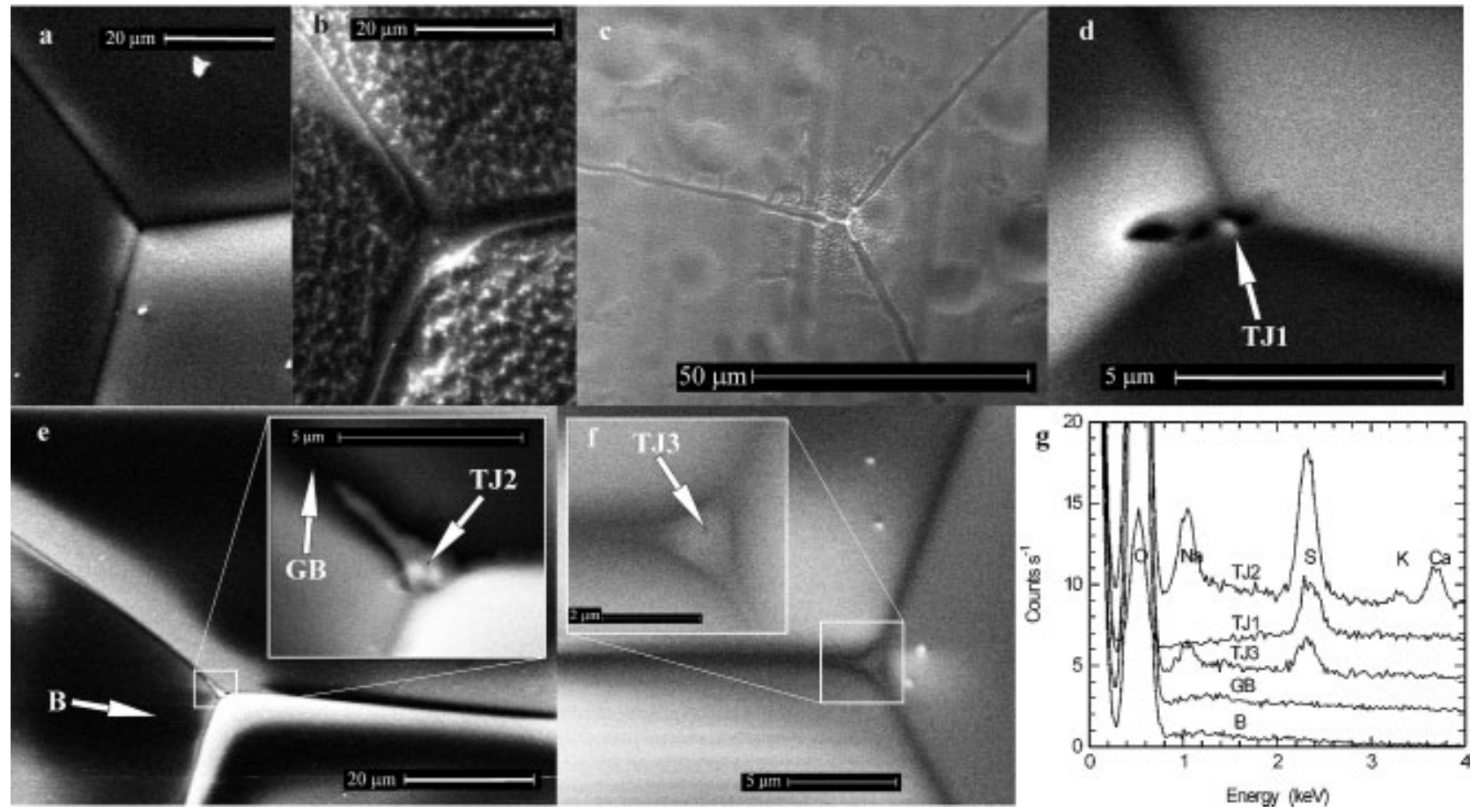

Fig. 6. Triple junctions. (a) Dome C ice from $243.30 \mathrm{~m}$, surface cut and pre-etched for 3 days. Although this ice contains a relatively high concentration of sulphate, no sulphur is detectable at the triple junction, although it is apparent on others on the specimen. The junction is also typical of those observed in background ice. (b) The triple junction seen in (a) after etching for 7 min at -80 ${ }^{\circ} \mathrm{C}$. A grain-boundary filament is visible in the etching channel, although the impurity is below the detection limit, both at the triple junction and in the filament. (c) Trace sodium and chlorine are revealed at this triple junction by 1 min of etching, at $-80^{\circ}$ C, of the surface of this Dome Cice from $501 \mathrm{~m}$ (the surface was not pre-etched). Note that grain-boundary filaments are visible close to the triple junction; they die out after around $15 \mu \mathrm{m}$. (d) A triple junction containing only sulphur ( T71) detected in Dome C ice from $243.30 \mathrm{~m}$. The surface was pre-etched for 1 day. The dark spot to the left of the triple junction is a hole that was burned by the electron beam. (e) A triple junction containing sulphur and other insoluble impurities ( TF2), found on the same specimen as (d). The grain boundary (GB) in the vicinity of the triple junction was not significantly different from the background spectrum $(B)$. ( $f$ ) Triple junction observed in Dome Cice from $218.95 \mathrm{~m}$, pre-etched for 7 days. A very clear filled triple-junction structure is apparent ( T.73) and the impurity appears to extend into the grain boundaries, although impurity is not detectable in these locations. ( $g$ ) X-ray spectra for $(d-f)$, offset by multiples of 2 counts $s^{-1}$.

the radius of the bond decreases during sublimation, the initially smooth band of coagulated impurity was observed to buckle as it sticks to the surface. The presence of $\mathrm{Mg}$ and $\mathrm{S}$ (Fig. 5c) in the filament on the uncut surface but not on the cut surface of the bond shown in Figure 5d may indicate the role of pre-etching in concentrating impurities on the specimen surface.

The freshly cut, then etched surface shown in Figure 5e is from Dome $\mathrm{C}$ at $243.30 \mathrm{~m}$, a depth that corresponds to an acidic sulphate layer (probably fallout from a volcanic eruption) with a meltwater concentration of about $5 \mu \mathrm{M}$ (Table 1). Filaments and particles have coagulated on the surface without etching channels, since there was no preetching. The relatively large quantity of ice sublimed from the surface $(600 \mu \mathrm{m})$ may have included a grain-boundary plane; its contents could be added to the bulk impurity already coagulated on the surface.

\subsection{Impurity at triple junctions}

For natural samples, impurity was not noted at triple junctions without some form of pre-etching or etching. Pre-etching the surface of a specimen after cutting was found to be the most reliable method for revealing impurity at triple junctions; the greater the duration of pre-etching, the greater the likelihood of detecting impurity; the implications of this are discussed in section 4.2. Even in ice containing high bulk concentrations of acid, impurity located at triple junctions was not always apparent after pre-etching. Triple junctions can be seen in Figure 6, prepared by a variety of methods and showing examples of triple junctions with and without impurity, and their appearance after etching. Impurity concentrated at triple junctions was normally observed only in ice that contained relatively high bulk concentrations of acid, except where etched filaments joined (e.g. Fig. 5e), as can be seen from Table 1.

\subsection{Bulk impurity and dislocations}

A significant quantity of impurity could be at defects within the ice lattice. Furthermore, impurity will be incorporated directly as inclusions. In addition to the spots of detectable impurity shown in Figures $3 \mathrm{~b}$ and $4 d$, Figure $7 \mathrm{a}$ shows further examples of spots built up on the surface of ice from a Dome $\mathrm{C}$ acidic layer. The spots progressively coagulated and separated throughout the etching process. They show trace of chlorine that was likely to have been at defects in the lattice (dissolved) before etching. Sublimation of around $140 \mu \mathrm{m}$ of ice has left coagulated hydrated impurity on the surface. Also shown are brighter spots or inclusions containing chlorine in greater quantities at the edge of etching channels. It is likely that these are formed by the advancing edges of the channels sweeping up the smaller spots.

The surface in Figure $7 \mathrm{~b}$ was featureless before etching. The etching spots also contain detectable levels of sodium, in contrast to the previous example, and a bulk inclusion of 
similar composition is also seen. However, the most striking features are the long filaments seen on the surface that do not appear to be connected to any grain boundaries or triple junctions. These sodium-chloride-filled filaments could be residues of impurity originating from dislocations within the bulk of the grain.

\section{IMPURITY ARRANGEMENT}

This section considers the implications of information presented (section 3) on the factors that determine how different impurities are distributed in the ice. First, the arrangement of soluble impurities on surfaces is discussed in light of the observations. A similar approach is applied to the distribution in veins and in the lattice. Following this we compare our observations and suggested model of impurity distribution with previous results.

\subsection{Grain-vapour surfaces and grain boundaries}

Filament ridges (i.e. a filament structure on top of a ridge generally observed at the base of etching channels) were noted at the majority of grain-boundary bonds in both Dome $\mathrm{C}$ and Halley snow samples after etching. We interpret this as indicating the presence of soluble impurity, although it was below the X-ray analysis detection limit in most cases. In sintering surface snow of $340 \mathrm{~kg} \mathrm{~m}^{-3}$, there is a surface area of around $26 \mathrm{~m}^{2} \mathrm{~kg}^{-1}$ (Dominé and others, 2002). Assuming a mean grain radius of $200 \mu \mathrm{m}$ and a bond radius of $100 \mu \mathrm{m}$ (Fig. 3a and other observations) we can calculate the approximate number of grains per kilogram to be $\left[917 \times 4 / 3 \pi\left(2 \times 10^{-4}\right)^{3}\right]^{-1} \approx 3 \times 10^{7} \mathrm{~kg}^{-1}$ and the mean bond area to be $3 \times 10^{-8} \mathrm{~m}^{2}$. The grain coordination number is approximately 3.2 neighbours per grain (Alley and others, 1986b), which gives 1.6 bond areas per grain. The grain-boundary area (i.e. the area of ice-ice interface) is then $1.6 \mathrm{~m}^{2} \mathrm{~kg}^{-1}$, a factor of 16 times less area than the airice interface.

It is illustrative to consider what proportion of this surface could be covered by impurity. For a liquid-like monolayer primarily composed of water molecules, there will be of the order of $\left[6 \times 10^{23}\left(\mathrm{~mole}^{-1}\right) \times 10^{6}\left(\mathrm{~g} \mathrm{~m}^{-3}\right) /\right.$ $\left.18\left(\mathrm{~g} \mathrm{~mole}^{-1}\right)\right]^{2 / 3} \approx 1 \times 10^{19}$ molecules $\mathrm{m}^{-2}$ of which, if we assume a concentration close to the eutectic, about $10 \%$ will be an impurity species. The monolayer would therefore require $1 \times 10^{18}$ molecules of impurity $\mathrm{m}^{-2}\left(\sim 1.7 \mu \mathrm{mol} \mathrm{m}^{-2}\right)$. This value will in reality be lower because of the influence of the surface interactions in such a thin layer (Wettlaufer, 1999), which will lower the equilibrium concentration below the eutectic. However, the surface impurity density for a liquid-like monolayer quoted above will be used as an example to estimate the coverage of grain boundaries. Typical bulk impurity concentrations at Dome $\mathrm{C}$ are around $1.5 \mu \mathrm{mol} \mathrm{L}^{-1}$ for the sodium and sulphate species, both of which are highly insoluble in the lattice. If all this impurity formed a monolayer, it would cover $1.5\left(\mu \mathrm{mol} \mathrm{kg}^{-1}\right) /$ $1.7\left(\mu \mathrm{mol} \mathrm{m}{ }^{-2}\right) \approx 0.9 \mathrm{~m}^{2} \mathrm{~kg}^{-1}$. This value is of a similar magnitude to the area of ice-ice interface (grain boundary) in the snow, but considerably less than the air-ice interface area, where only about $3 \%$ would be covered by any one species. In the case of Halley snow where sodium and chlorine concentrations are around $20 \mu \mathrm{mol} \mathrm{L}^{-1}$, there is potential for a much higher proportion of the snow surface to be
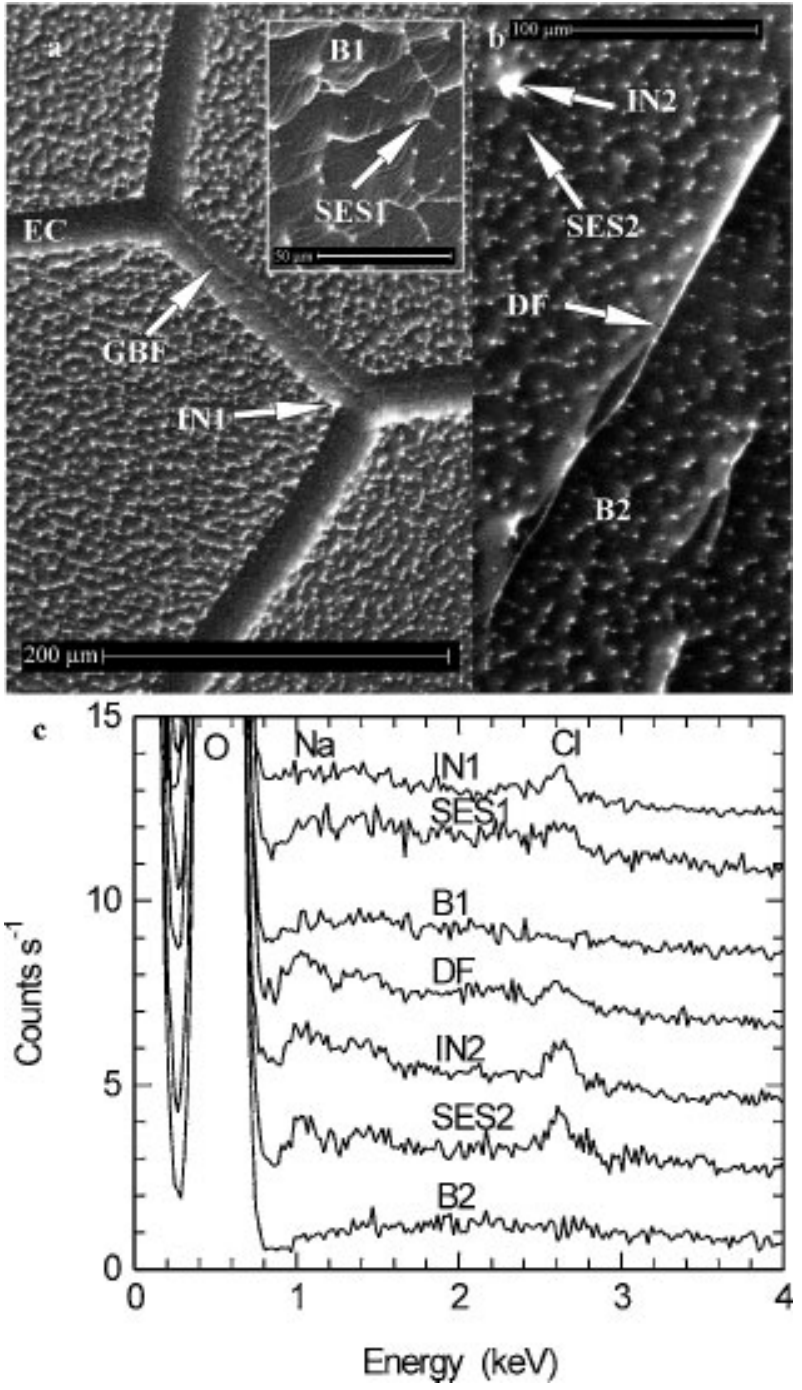

Fig. 7. Bulk impurity and inclusions. (a) Dome C ice from $218.95 \mathrm{~m}$, pre-etched for 7 days and then etched for $7 \mathrm{~min}$ at $-70^{\circ} \mathrm{C}$. Etch channels (EC) show original location of the grain boundaries; some contain filaments (GBF). Surface etching spots developed on surface (see inset) in which only chlorine was arguably detectable (SES1). Either inclusions or coagulated surface etch spots (IN1) are located on the rim of the etching channels. (b) Dome C ice from $243.50 \mathrm{~m}$, preetched for 10 days and etched for $5 \mathrm{~min}$ at $-70^{\circ} \mathrm{C}$. The surface imaged was located in the centre of a grain that was featureless before etching. Disconnected filaments are revealed, which may be indicative of impurity located at dislocations (DF). A bulk inclusion has also been revealed (IN2), which has a similar composition to the surface etching spots (SES2). These can be compared with the dark background (B2). (c) X-ray spectra for ( a) after 10 min at $-70^{\circ} \mathrm{C}$ and ( $b$ ), offset by multiples of 2 counts $s^{-1}$.

coated if aerosol inclusions are available in liquid form during the summer.

From these considerations we can surmise that, even if all impurity is on snow-grain surfaces, the impurity is almost certainly distributed heterogeneously, with coatings (possibly more than a monolayer thick) on some grains and absent on others (see Fig. 3a). The evidence suggesting that impurity is resident at many bonds therefore implies that it is energetically preferable for at least one of the impurity species to exist at a grain boundary as opposed to a grain surface. On the few occasions when impurity was detectable 
in snow and upper firn at filaments, sulphate ions were common to all examples, although invariably in conjunction with other ions (Table 1). The only location where sulphate ions were observed originating from the grain surface was on the rim of a bubble in ice from an acidic sulphate layer in which the concentration of sulphate was high enough to coat all available grain boundaries with at least a monolayer (an acidic bulk concentration of $5.2 \mu \mathrm{mol} \mathrm{L}^{-1}$ could cover up to $\sim 3 \mathrm{~m}^{2} \mathrm{~kg}^{-1}$ with a monolayer; the available grain boundary at this depth is around $2.2 \mathrm{~m}^{2} \mathrm{~kg}^{-1}$ ).

At other depths less rich in sulphate, a far smaller proportion of boundaries were filled, and elements detected in filaments tended to be sodium and chlorine, indicating their presence at grain boundaries (Table 1; Fig. 5e). Filaments containing detectable impurity were observed coagulating at the rims of bubbles during etching (Fig. 4b). This implies that the impurity originated from the bubble surfaces and was observed in specimens where bulk impurity concentrations were insufficient to coat all grain boundaries (at concentrations of the magnitude proposed), suggesting a possible affinity of sodium for grain-vapour interfaces in preference to grain boundaries. Whatever the case, it seems clear that impurity is again heterogeneously distributed at grain boundaries. The likelihood of a boundary being occupied is probably dependent in part on its relative lattice orientations. Closely aligned crystals are likely to exclude impurity from their interface, while the presence of an impurity layer between two lattices of different orientation may be favourable.

The concentration of impurity situated at a grain boundary can be inferred from observation of a filament on an etched surface, for example the filament seen at GBF2 in Figure 5e. The X-ray signal strength emitted from this filament is of a similar magnitude to that generated by the $0.5 \mathrm{~mol} \mathrm{~L}^{-1}$ standard frozen into a $0.4 \mu \mathrm{m}$ hole discussed in section 2.1. If $1 \mu \mathrm{m}$ of the filament has been stimulated to produce this signal then we expect about $1 \times 10^{-16} \mathrm{~mol}$ of impurity per micrometre of filament, the radius of the filament is $200 \mathrm{~nm}$, so the concentration of hydrated salt is $\sim 1 \mathrm{~mol} \mathrm{~L}^{-1}$, which is of the same order as the eutectic composition. This filament was created by sublimation through up to $600 \mu \mathrm{m}$ of grain boundary. If the whole of the boundary were perpendicular to the direction of sublimation and covered with a monolayer of impurity (at the concentration proposed for liquid-like properties) then we would expect a coagulation of $1 \times 10^{-6}(\mathrm{~m}) \times 600 \times$ $10^{-6}(\mathrm{~m}) \times 1.7 \mu \mathrm{mol} \mathrm{m}^{-2} \approx 1 \times 10^{-15} \mathrm{~mol}$ of impurity per micrometer of filament, which is an order of magnitude more than observed in this case. It is likely that the impurity, when present, is at a lower concentration than the eutectic because of attractive interfacial forces; the whole of the grain boundary is unlikely to have been perpendicular to the surface, and not all impurity will have necessarily coagulated in the observed filament. However, the calculation is consistent with a heterogeneous distribution of impurity at grain boundaries, with much of the boundary containing no impurity.

The reasoning above relies on the assumption that impurity at a grain boundary exists in a monolayer at concentrations close to the eutectic concentration, i.e. it is behaving in a liquid-like manner. It is quite possible that this may not be the case and that the ionic species could disperse to greater dilutions at the grain boundaries through diffusion. Grain-boundary diffusivities for ions in ice are not well known. However, images indicating incomplete coverage of grain boundaries (e.g. Fig. 5b) are suggestive of a liquidlike layer covering the maximum possible boundary area allowed by the liquidus relation and interfacial forces for impurity spread at a boundary; further dilution by diffusion would cause an apparent phase change (i.e. a reduction in impurity concentration to a level where liquid-like properties are no longer exhibited), hence locking the impurity in place.

\subsection{Triple junctions}

Impurity was generally only detected at triple junctions in specimens where a high concentration of sulphate ions was present. Pre-etching served to concentrate acid at the triple junctions, probably by the slow loss of mass from the surface during pre-etching. It is theoretically possible that impurity collected at triple junctions by pre-etching could have originated from the cut surface; however, this is unlikely, at least for sulphate ions. Sulphate ions were not generally observed in immobile surface etching spots, suggesting that they were not present in the bulk of grains. The dimensions of filled triple junctions seemed to be related to pre-etch time and bulk concentration, and the largest triple junctions observed on pre-etched surfaces had areas of several square microns. When compared with spectra from $4.9 \mathrm{~mol} \mathrm{~L}^{-1}$ sulphuric acid frozen into $2 \mu \mathrm{m}$ holes, the triple junction in Figure 6e produced a signal consistent with the entire electron interaction volume containing impurity at the eutectic concentration. However, the X-ray spectra collected from other triple junctions gave smaller signals, which were consistent with the production of X-rays close to the surface only. For example, the triple junction in Figure 6d, which has a surface area of $\sim 1.4 \mu \mathrm{m}^{2}$, produced a signal strength that could be explained by X-ray emission from impurity at the eutectic composition extending to $\sim 0.4 \mu \mathrm{m}$ depth. When triple junctions were etched, no clear vein residues were revealed (often only grain-boundary filaments and etching spots were detectable (e.g. Fig. 6b)). Furthermore, impurity was never detectable at triple junctions on freshly cut surfaces, even in ice from the acidic layers, where preetched images show veins with areas of several square microns. This could, however, be an artefact of the cooling wave penetrating the specimen from the surface inwards during its immersion in liquid nitrogen; cooling specimens from the base up could test this possibility. It appears highly unlikely that veins have a diameter as large as the cross-sections observed on a pre-etched surface. It is more plausible that far narrower veins are the source for the impurity, which collects in the rotting triple junctions formed during pre-etching (Nye, 1991). Without data to constrain the rate of sublimation during pre-etching, it is difficult to estimate the vein dimensions below the surface. A similar process may well take place when filaments are formed during pre-etching. It is less likely that surface spots have a similar source since they have not been observed before etching.

Although sulphate ions were found alone in some cases (e.g. Fig. 6d), indicating the presence of sulphuric acid, it was more usual for a combination of ions to be present, particularly sulphate and sodium, suggesting that the following reaction had occurred:

$$
\mathrm{H}_{2} \mathrm{SO}_{4}+2 \mathrm{NaCl} \rightarrow \mathrm{NaSO}_{4}+2 \mathrm{HCl},
$$

allowing the $\mathrm{H}^{+}$and $\mathrm{Cl}^{-}$ions to dissolve into the lattice and leaving a sodium sulphate residue at the veins mixed with 
any excess acid. This is consistent with the high lattice solubility of chloride ions compared to the other species present (Petrenko and Whitworth, 1999). Chloride ions were not noted at triple junctions in any of the sulphate peaks. Similar reactions are likely with the other cations and would also release the chloride ions into the lattice.

A relatively high concentration of sulphate in the bulk ice appears necessary for impurity to be detectable at triple junctions. This is consistent with either saturation of the surrounding ice lattice, forcing any excess to concentrate at triple junctions, or a saturation of the surrounding grain boundaries with an impurity layer, allowing the excess to concentrate in a vein. In this study, the lowest bulk concentration of sulphate ions for which filled triple junctions were detectable was $1.6 \mu \mathrm{mol} \mathrm{L}{ }^{-1}$. This could represent either an upper limit at which the surrounding ice $\left(\right.$ at $-53^{\circ} \mathrm{C}$ and this particular grain-size) is saturated, or perhaps more probably the bulk concentration at which sufficient grain boundaries are saturated to allow the collection of ice at some triple junctions.

\subsection{Interface energies}

The observed boundary interface angles (vapour-ice-ice in section 3.1. and ice-impurity-ice in Fig. 6) have implications for boundary interface energies and hence impurity distribution. At a steady-state interface between a grain boundary and air, the ice-vapour surface free energies are balanced by the grain-boundary free energy (Hobbs, 1974, p. 436-441). Thus the dihedral angle of the grain boundary groove (which must form to achieve equilibrium) is indicative of the surface energies of the system. The dihedral contact angle found here of $132 \pm 3^{\circ}$ is significantly less than the grain-boundary contact angle of $145^{\circ}$ quoted by Hobbs for pure ice measured at $0^{\circ} \mathrm{C}$. The value seems more consistent with those quoted for unclean ice, which contained many surface irregularities, particularly at the grain boundaries, where the dihedral angles were $130-148^{\circ}$.

The reduction in the dihedral angle implies a reduction in the ratio of ice-vapour to grain-boundary surface free energy $\left(\gamma_{\text {iv }} / \gamma_{\text {ii }}\right)$ (Hobbs, 1974, p. 436-441), from 1.67 to 1.23 . This is hard to reconcile with the earlier observation of impurity preferentially located at grain boundaries between snow bonds (section 4.1), which requires $\gamma_{\mathrm{ii}}$ to be reduced by the introduction of impurities. It may be explained by a significant reduction in $\gamma_{\text {iv }}$ caused by the lower observation temperature $\left(-20^{\circ} \mathrm{C}\right)$ and/or the addition of an impurity layer to the surface. Relevant interfacial energy information is not currently available to test this.

Figure 6e appears to show no sign of impurity in the grain boundaries surrounding the triple junction, although the salty composition (the following impurities were detected: $\mathrm{Na}, \mathrm{S}, \mathrm{K}$ and $\mathrm{Ca}$ ) may indicate a solid precipitate. Etching the junction suggested the presence of trace impurity at the grain boundaries. Figure 6c shows sodium and chlorine extending a short distance from the grain boundary into the triple junction. Figure 6f, however, shows that the dihedral angle at the triple junction is zero or very close to zero. It is not clear whether this also characterizes the dihedral angle of the vein below the surface, as the vein cross-section is expected to widen like a funnel towards the surface (see section 4.2.).

At temperatures close to $0^{\circ} \mathrm{C}$, liquid was not present at grain boundaries in studies of laboratory ice where dihedral angles around $32^{\circ}$ were observed (Mader, 1992), implying $1.9 \gamma_{\mathrm{il}}=\gamma_{\mathrm{ii}}$, where $\gamma_{\mathrm{il}}$ is the ice-liquid interface energy. The concentration of solute in the veins was low enough to have a negligible impact on $\gamma_{\mathrm{il}}$. At the temperatures typical in polar ice (e.g. $-53^{\circ} \mathrm{C}$ at Dome $\mathrm{C}$ ), the higher intergranular solute concentrations could be sufficient to reduce $\gamma_{\text {il }}$ such that $2 \gamma_{\mathrm{il}} \leq \gamma_{\mathrm{ii}}$, allowing distribution of a layer of solute at grain boundaries to be energetically favourable. This is also borne out by the widespread observation of filaments at grain boundaries, both in other work (e.g. Cullen and Baker, 2000) and here. Under our proposed scenario, if a liquidlike layer of solute is situated at a grain boundary, any excess will locate at the triple junction because of curvature effects. Different ionic species will have varying effects on $\gamma_{\mathrm{il}}$ or $\gamma_{\mathrm{ii}}$, which might account for the apparent preference of salts for grain boundaries over veins. Note that at Dome $\mathrm{C} \mathrm{NaCl}$ is present below its eutectic temperature and is therefore unlikely to behave like a liquid; however, it may still be able to reduce $\gamma_{\mathrm{ii}}$, making its location at grain boundaries preferable to inclusion in the lattice. If it does not behave like a liquid, $\mathrm{NaCl}$ will have no significant energetic preference for triple junctions. Its significant presence at triple junctions in acidic ice (Fig. 6e and f) could be explained by diffusion from grain boundaries to the vein to fuel the reaction given by Equation (1).

The SEM techniques applied in this work could be used to test the impact of impurities on boundary interface energies in laboratory-grown ice prepared at different temperatures, presuming that sufficient time was available for the specimens to reach equilibrium.

\subsection{Lattice}

Immobile spots of impurities that have coagulated on the surface during etching appear to originate directly from impurity previously dissolved or included in the lattice (except in the relatively unlikely case where a grain-boundary layer is deposited on the surface). The most commonly detected impurity in these spots was chlorine, particularly in the specimens from the acidic sulphate layers. It is likely that the chlorine, when detected alone, was originally deposited in a salty form, which has subsequently been liberated by the reaction given by Equation (1).

As an example, we estimate the quantity of chloride dissolved in the bulk for Dome C ice at 218.95 m (Fig. 7a). Chloride is just above the detection limit in the surface etch spots after $10 \mathrm{~min}$ at $-70^{\circ} \mathrm{C}$, by which time approximately $200 \mu \mathrm{m}$ of ice had been sublimed from the surface. The number of surface spots per unit of etched volume is $1.4 \times 10^{13} \mathrm{~m}^{-3}$, so assuming that a spot contains approximately $3 \times 10^{-17} \mathrm{~mol}$ of chloride (section 2.1), the bulk concentration is $\sim 0.4 \mu \mathrm{mol} \mathrm{L}^{-1}$; we estimate an uncertainty of at least $50 \%$ on this calculation. However, it is consistent with the majority of the chloride in the ice, which has a bulk concentration of $0.4 \mu \mathrm{mol} \mathrm{L}^{-1}$, being dissolved in the lattice; it is considerably below the lattice solubility limit of $\sim 600 \mu \mathrm{mol} \mathrm{L}^{-1}$ for $\mathrm{HCl}$ at $-53.5^{\circ} \mathrm{C}$ found by Thibert and Dominé (1997).

In other cases where impurity was detectable, a combination of sodium and chlorine was often noted, although generally in larger, less regularly spaced spots than those containing chlorine alone, perhaps indicating impurity inclusions disrupting the lattice. Non-acidic chloride ions could only be substituted for $\mathrm{H}_{2} \mathrm{O}$ molecules if an associated cation was also included interstitially within the ice 
molecular cage to prevent charge separation. The amount dissolved is strongly dependent on the equilibrium partition co-efficient, or solubility limit of the lattice. The possible dislocations observed in Figure $7 \mathrm{~b}$ could be the result of an amalgamation of inclusions formed to reduce the lattice free energy.

\subsection{Arrangement summary}

Our best assessment of the arrangement of impurities is as follows:

Chloride is found in the lattice, probably because of its solubility. Traces of other impurities originating from the lattice were less common, except as inclusions.

There is evidence that other impurities, particularly sodium chloride, coat bubble surfaces and grain boundaries heterogeneously.

Where there is a high bulk concentration, acidic sulphate is often found at triple junctions, frequently in conjunction with other cations.

\subsection{Comparison with previous work}

Some of the observed differences in the distribution previously noted are linked to small differences in the technique of the different groups. In this work we have noted all the features observed in the previous studies as well as new variations of them. The features of impurity filaments and inclusions observed in studies on Greenland (GISP2) and Antarctic (Byrd core) ice (Cullen and Baker, 2000, 2001; Baker and Cullen, 2002) are seen in many specimens here when prepared by a similar method: pre-etching followed by etching. Our conclusion that these studies could have had difficulty locating triple junctions accurately on the specimen surfaces makes their findings regarding veins doubtful except in cases where filaments are joined at triple junctions. The sulphate-filled veins observed in acidic layers of $\mathrm{H}_{2} \mathrm{SO}_{4}$ seen in this work are consistent with studies of acidic Antarctic ice from Dolleman Island (Mulvaney and others, 1988; Wolff and others, 1988). However, the absence of detectable impurity in veins from less acidic ice casts some doubt on the concept of a fully connected network of impurity-filled veins in the ice sheet. Without the presence of impurities, vein diameters are negligibly small $\left(\sim 10^{-10} \mathrm{~m}\right)$ except in the warmer regions of the ice sheet, such as near the base. A more likely model includes layers of connected veins at depths where sulphate ions are already covering the majority of neighbouring grain boundaries at least in a monolayer. Triple junctions at other less acidic depths would contain little more impurity than the surrounding grain boundaries.

The study of Antarctic ice by Fukazawa and others (1998) found acidic $\mathrm{SO}_{4}{ }^{2-}, \mathrm{HSO}_{4}{ }^{-}$and $\mathrm{NO}_{3}{ }^{-}$ions present in veins at $-20^{\circ} \mathrm{C}$ using Raman spectroscopy. They did not detect these species at grain boundaries, possibly because of the detection limit of the technique. The ice from both sites contained high concentrations of sulphuric acid $\left(3.42 \mu \mathrm{mol} \mathrm{L}{ }^{-1}\right.$ at Nansen and $14.35 \mu \mathrm{mol} \mathrm{L}^{-1}$ at South Yamato), which is consistent with the results seen here. In the case of the South Yamato ice, where only $3 \%$ of the acid was estimated to reside at triple junctions, a vein dihedral angle close to zero (as observed here) might allow a significant volume of this acid to spread into the grain boundaries, in addition to a monolayer. They also observed acidic nitrate ions in veins, but these cannot be detected by the technique used here. The chloride ions apparently dissolved in the lattice are below the solubility limit found by Thibert in laboratorygrown ice (Thibert and Dominé, 1997).

\subsection{Implications}

The heterogeneous distribution of impurity observed in specimens of low impurity content is interpreted to imply an absence of connected impurity-filled pathways either at grain boundaries or at veins. At higher bulk concentrations the greater proportion of grain boundaries coated by impurity will increase the connectivity between grain boundaries displaying liquid-like properties due to impurity coating. If grain boundaries are covered or saturated with at least a monolayer of impurity locally then there will be increasing connection between filled veins. Hence a vertically connected network of impurity-filled veins is extremely unlikely in areas of an ice sheet with low temperature and background impurity levels such as Dome C. However, horizontally connected networks of impurity-filled vein remain quite feasible within sulphuric acid layers. The likelihood of connection in either veins or grain boundaries will be dependent on impurity content, grain-size and temperature. Impurity-coating the surfaces of bubbles should link unconnected veins within acidic layers.

The theory of electrical conduction through sulphuricacid-filled veins (Wolff and Paren, 1984) remains applicable in cases where bulk concentration is high enough to saturate the surrounding grain boundaries and hence fill the veins. At lower bulk concentrations, another conductivity mechanism is required, perhaps by the mobilization of protonic defects from the heterogeneous patches of impurity at grain boundaries. The ionization defects are then free to travel either along grain boundaries or through the lattice. In regions where $\mathrm{NaCl}$ reacts with $\mathrm{H}_{2} \mathrm{SO}_{4}$ at triple junctions (Equation (1)), the release of $\mathrm{H}^{+}$and $\mathrm{Cl}^{-}$ions into the lattice should allow conduction via ionization defects in the lattice (Petrenko and Whitworth, 1999) to replace the liquid conduction lost from the vein.

This explanation of conduction is in good agreement with the work of Fujita (Fujita and others, 2002) who noticed a step increase in the conductivity of Dome $\mathrm{F}$ ice from sulphuric acid layers $\left(10-20 \mu \mathrm{mol} \mathrm{L}^{-1}\right)$ as the temperature was increased above $-81^{\circ} \mathrm{C}$. They explained this by the addition of liquid conduction to the total conductivity as the frozen aqueous mixture melted in the veins at around its eutectic temperature. When the experiment was repeated on ice with background impurity levels, the step change in conductivity was not seen, implying the absence of significant quantities of soluble impurity in veins.

Dust particles have been located at grain boundaries, in some cases visibly pinning them (Barnes and others, 2002b). The widespread observation of soluble impurity species at grain boundaries in this work suggests that the post-depositional production of $\mathrm{CO}_{2}$ suggested by Tschumi and Stauffer (2000) is feasible, although determining the rate will be complicated by factors such as the grain-boundary diffusivity, since this will dictate the pace of acid reaching the dust.

Water molecules confined to sub-nanometre spaces such as those at grain boundaries are thought to adopt a structured arrangement (e.g. Gallo and others, 2000; Pollack, 2001); this could reduce the diffusivity of aqueous ionic 
impurities confined at the boundaries. However, Raviv and others (2001) found the viscosity of highly purified water within sub-nanometre films to be close to that of the bulk liquid, suggesting that the diffusivity of water is similarly unaffected by confinement. They emphasize, however, that the addition of hydrated ions to the layer could alter the behaviour of the film. If the diffusivities of aqueous ions are significantly reduced by confinement at grain boundaries, the shift of the chemical profile by the mechanism described by Rempel and others (2001b) would be slowed. Liquid displaying bulk properties would only be present in veins contained by regions of relatively high bulk concentration. Diffusion of solute under a temperature gradient would be limited by the diffusion of solute from veins into unfilled grain boundary. This could provide an alternative explanation for movement of solute noted in the upper layers of the Dome $\mathrm{C}$ ice core (Barnes and others, 2002a).

\section{CONGLUSION}

Impurity has been located on grain surfaces, boundaries, triple junctions and lattice in ice from four different polar sites. The results are consistent with previous observation of impurities in polar ice by a number of different techniques. The preferred arrangement of impurities appears to be complex and dependent on the chemical composition and probably the temperature of the ice. Layers of impurity containing $\mathrm{NaCl}$ and other sea salts form at grain boundaries. Sulphate ions, probably acidic, are also located at grain boundaries. When sulphuric acid is present in sufficient bulk concentration (observed here to be around $1.6 \mu \mathrm{mol} \mathrm{L}^{-1}$ for one example of Dome $\mathrm{C}$ ice), the acid is able to congregate in detectable quantities in veins. Consequently, the proportion of acid distributed in veins is almost certainly dependent on both the total concentration of acid in the ice and the grain-size. At this location it may react with salts from the surrounding grain boundaries, releasing acidic chloride ions into the lattice or grain boundaries. The proposed distribution appears consistent with models of electrical conductivity. Impurity arranged in this fashion would be unlikely to allow significant long-distance transport of interstitial impurity through the ice under the action of a temperature gradient unless the impurity content were consistently much greater than the levels observed in deep polar ice cores or at temperatures approaching the bulk melting point.

The impurity distribution proposed here on the basis of our observations will be of interest to a variety of glaciological fields, a few of which are mentioned below. The electrical conductivity mechanisms at work will vary depending on bulk impurity content and grain structure. Hence the calibration of dielectric profile (DEP) and electrical conductivity measurements (ECM) on ice cores will be slightly altered and can no longer be considered to be solely dependent on the bulk chemistry content. The distribution is also directly relevant to the mobility of species in the ice, and we see that at high bulk concentrations soluble species will be significantly more mobile than when they are present in trace amounts and only patchily coating grain boundaries. The possibility of post-depositional reaction between dust particles and soluble impurities at grain boundaries is also confirmed.

\section{ACKNOWLEDGEMENTS}

This work is a contribution to the European Project for Ice Coring in Antarctica (EPICA), a joint European Science Foundation/European Commission (EC) scientific programme, funded by the EC and by national contributions from Belgium, Denmark, France, Germany, Italy, the Netherlands, Norway, Sweden, Switzerland and the United Kingdom. This is EPICA publication No. 67. We thank A. Rempel for comments and discussion on this work.

\section{REFERENGES}

Adams, E. E., D. A. Miller and R. L. Brown. 2001. Grain boundary ridge on sintered bonds between ice crystals. 7. Appl. Phys., 90 (11), 5782-5785.

Alley, R. B., J. H. Perepezko and C. R. Bentley. 1986a. Grain growth in polar ice: I. Theory. f. Glaciol., 32(112), 415-424.

Alley, R. B., J. H. Perepezko and C. R. Bentley. 1986b. Grain growth in polar ice: II. Application. f. Glaciol., 32(112), 425-433.

Baker, I. and D. Cullen. 2002. The structure and chemistry of $94 \mathrm{~m}$ Greenland Ice Sheet Project 2 ice. Ann. Glaciol., 35, 224-230.

Barnes, P. R. F. 2003. Comment on "Grain boundary ridge on sintered bonds between ice crystals" [J.Appl.Phys., vol. 90, 5782-5785 (2001)]. 7. Appl. Phys, , 93(1), 783-785.

Barnes, P. R. F., H. M. Mader, R. Röthlisberger, R. Udisti and E.W. Wolff. 2002a. The evolution of chemical peak shapes in the Dome $\mathrm{C}$ ice core, Antarctica. 7. Geophys. Res., 108(D3). (10.1029/2002JD002538.)

Barnes, P. R. F., R. Mulvaney, K. Robinson and E. W. Wolff. 2002b. Observations of polar ice from the Holocene and the glacial period using the scanning electron microscope. Ann. Glaciol., 35, 559-566.

Barnes, P. R. F., R. Mulvaney, E.W. Wolff and K. Robinson. 2002c. A technique for the examination of polar ice using the scanning electron microscope. J. Microsc., 205 (2), 118-124.

Colbeck, S. C. 1998. Sintering in a dry snow cover. 7. Appl. Phys., 84(8), 4585-4589.

Cullen, D. and I. Baker. 2000. Correspondence. The chemistry of grain boundaries in Greenland ice. F. Glaciol., 46(155), 703-706.

Cullen, D. and I. Baker. 2001. Observation of impurities in ice. Microsc. Res. Techn., 55, 198-207.

Davy, J. G. and D. Branton. 1970. Subliming ice surfaces: freeze-etch electron microscopy. Science, 168(3936), 1216-1218.

Dominé, F., A. Cabanes and L. Legagneux. 2002. Structure, microphysics and surface area of the Arctic snowpack near Alert during ALERT 2000 campaign. Atmos. Environ., 36(15-16), 2753-2765.

Echlin. 1992. Low-temperature microscopy and analysis. First edition. New York, Plenum.

Fujita, S. and 9 others. 2002. Linear and non-linear relations between highfrequency-limit conductivity, AC-ECM signals and ECM signals of Dome F Antarctic ice core from a laboratory experiment. Ann. Glaciol., 35, 321-328.

Fukazawa, H., K. Sugiyama, S. Mae, H. Narita and T. Hondoh. 1998. Acid ions at triple junction of Antarctic ice observed by Raman scattering. Geophys. Res. Lett., 25(15), 2845-2848.

Gallo, P., M. Rovere and E. Spohr. 2000. Glass transition and layering effects in confined water: a computer simulation study. 7. Chem. Phys, $\mathbf{1 1 3}(24), 11,324-11,335$.

Harrison, W. D. and C. F. Raymond. 1976. Impurities and their distribution in temperate glacier ice. F. Glaciol., 16(74), 173-181.

Hobbs, P. V. 1974. Ice physics. Oxford, Clarendon Press.

Kumai, M. 1976. Identification of nuclei and concentrations of chemical species in snow crystals sampled at the South Pole. 7. Atmos. Sci., 33(15), 833-841.

Mader, H. M. 1992. The thermal behaviour of the water-vein system in polycrystalline ice. F. Glaciol., 38(130), 359-374.

Mulvaney, R., E.W. Wolff and K. Oates. 1988. Sulphuric acid at grain boundaries in Antarctic ice. Nature, 331 (6153), 247-249.

Nye, J.F. 1991. The rotting of temperate ice. f. Cryst. Growth, 113(3-4), 465-476.

Nye, J. F. and F. C. Frank. 1973. Hydrology of the intergranular veins in a temperate glacier. International Association of Scientific Hydrology Publication 95 (Symposium at Cambridge 1969 - Hydrology of Glaciers), 157-161.

Oates, K. and W.T.W. Potts. 1985. Electron-beam penetration and X-rayexcitation depth in ice. Micron and Microscopica Acta, 16(1), 1-4.

Petrenko, V. F. and R. W. Whitworth. 1999. Physics of ice. Oxford, etc., Oxford University Press.

Pollack, G. H. 2001. Cells, gells and the engines of life. First edition. Seattle, Ebner and Sons. 
Rango, A., W. P. Wergin and E. F. Erbe. 1996a. Snow crystal imaging using scanning electron microscopy: 1. Precipitated snow. Hydrol. Sci. F., 41 (2), 219-233.

Rango, A., W. P. Wergin and E. F. Erbe. 1996b. Snow crystal imaging using scanning electron microscopy: 2. Metamorphosed snow. Hydrol. Sci. F., $41(2), 235-250$

Raviv, U., P. Laurat and J. Klein. 2001. Fluidity of water confined to subnanometre films. Nature, 413(6851), 51-54

Reid, A. P., W.T.W. Potts, K. Oates, R. Mulvaney and E. Wolff. 1992. Preparation of aqueous standards for low temperature X-ray microanalysis. Microsc. Res. Techn., 22(2), 207-211.

Rempel, A.W., J. S. Wettlaufer and M. G. Worster. 2001a. Interfacial premelting and the thermomolecular force: thermodynamic buoyancy. Phys. Rev. Lett., 87(8), 88,501-88,504.

Rempel, A. W., E. D. Waddington, J. S. Wettlaufer and M. G. Worster. 2001b. Possible displacement of the climate signal in ancient ice by premelting and anomalous diffusion. Nature, 411 (6837), 568-571.

Röthlisberger, R. and 6 others. 2000. Technique for continuous high-resolution analysis of trace substances in firn and ice cores. Environ. Sci. Technol., $34(2), 338-342$.
Thibert, E. and F. Dominé. 1997. Thermodynamics and kinetics of the solid solution of HCl in ice. F. Phys. Chem., Ser. B, 101(18), 3554-3565.

Tschumi, J. and B. Stauffer. 2000. Reconstructing past atmospheric $\mathrm{CO}_{2}$ concentration based on ice-core analyses: open questions due to in situ production of $\mathrm{CO}_{2}$ in ice. 7. Glaciol., 46(152), 45-53.

Udisti, R. and 6 others. 2000. Holocene electrical and chemical measurements from the EPICA-Dome C ice core. Ann. Glaciol., 30, 20-26.

Weiss, J., J. Vidot, M. Gay, L. Arnaud, P. Duval and J. R. Petit. 2002. Dome Concordia ice microstructure: impurities effect on grain growth. Ann. Glaciol., 35, 552-558.

Wettlaufer, J. S. 1999. Impurity effects in the premelting of ice. Phys. Rev. Lett., 82(12), 2516-2519.

Wolff, E.W. and J. G. Paren. 1984. A two-phase model of electrical conduction in polar ice sheets. F. Geophys. Res., 89(B11), 9433-9438.

Wolff, E.W., R. Mulvaney and K. Oates. 1988. The location of impurities in Antarctic ice. Ann. Glaciol., 11, 194-197.

Wolff, E.W., W. D. Miners, J. C. Moore and J. G. Paren. 1997. Factors controlling the electrical conductivity of ice from the polar regions - a summary. F. Phys. Chem., 101 (32), 6090-6094. 